\title{
A MULTIMODALIDADE \\ NAS REVISTAS ELETRÔNICAS \\ GERENCIADAS PELO \\ OPEN JOURNAL SYSTEMS(OJS) \\ A PARTIR DA PERSPECTIVA DA SEMIÓTICA SOCIAL
}

\section{LA MULTIMODALIDAD EN REVISTAS ELECTRÓNICAS GESTIONADAS POR EL OPEN JOURNAL SYSTEMS (OJS) DESDE LA PERSPECTIVA DE LA SEMIÓTICA SOCIAL}

\author{
MULTIMODALITY IN ELECTRONIC JOURNALS MANAGED BY THE OPEN JOURNAL \\ SYSTEMS (OJS) FROM THE PERSPECTIVE OF SOCIAL SEMIOTICS
}

Leila Rachel Barbosa Alexandre*

Universidade Federal de Minas Gerais | Universidade Federal do Piauí

\begin{abstract}
RESUMO: O presente artigo objetiva analisar, considerando a perspectiva da Semiótica Social, a organização multimodal de revistas acadêmicas eletrônicas produzidas e geridas pelo Open Journal Systems (OJS) a partir dos quatro domínios relacionados à construção de significados dos textos multimodais: discurso, design, produção e distribuição. Em virtude desse objetivo, tomamos como base teórica, principalmente, Kress e Van Leeuwen $(2001,2006)$ e Kress $(2003,2015)$ e analisamos, além de exemplares dessas revistas eletrônicas, informações constantes no manual que trata da utilização do OJS. Tendo em vista a análise empreendida, foi possível verificar forte influência das ideologias da comunidade discursiva acadêmica e das suas práticas tradicionais em meio impresso na orquestração multimodal das revistas analisadas.
\end{abstract}

PALAVRAS-CHAVE: Semiótica Social. Multimodalidade. Revistas acadêmicas eletrônicas.

RESUMEN: Este artículo tiene como objetivo analizar, teniendo en cuenta la perspectiva de la Semiótica Social, la organización multimodal de revistas académicas electrónicas producidas y gestionadas por el Open Journal Systems (OJS) a partir de los cuatro dominios relacionados con la construcción de significados de textos multimodales: discurso, diseño, producción y distribución. Debido a este objetivo, se toma como base teórica, principalmente, Kress y Van Leeuwen (2001, 2006) y Kress (2003, 2015) y se analizan, así como ejemplares de esas revistas electrónicas, la información contenida en el manual que se ocupa del uso del OJS. En vista del análisis realizado, se observó una fuerte influencia de las ideologías de la comunidad de discurso académico y sus prácticas tradicionales en medio impreso en la orquestación multimodal de las revistas analizadas.

PALABRAS-CLAVE: Semiótica Social. Multimodalidad. Revistas académicas electrónicas.

*Doutoranda em Estudos Linguísticos pela Universidade Federal de Minas Gerais. Professora da Universidade Federal doPiauí. E-mail: leilarachel@gmail.com. 
ABSTRACT: The present article aims to analyze, considering the perspective of the Social Semiotics, the multimodal organization of electronic academic journals produced and managed by the Open Journal Systems (OJS) from the four domains related to the construction of meanings of the multimodal texts: discourse, design, production and distribution. Because of this goal, we use mainly Kress and Van Leeuwen $(2001,2006)$ and Kress $(2003,2015)$ as the theoretical basis, and we analyze both the issues of these electronic journals and the information from the manual that deals with the use of the OJS. Considering the analysis performed, it was possible to verify a strong influence of the ideologies of the academic discourse community and of its traditional practices in print media in the multimodal orchestration of the analyzed journals.

KEYWORDS: Social Semiotics. Multimodality. Electronic academic journals.

\section{INTRODUÇÃO}

Ao observarmos as influências das novas tecnologias de informação e comunicação para as práticas textuais tradicionais, não raramente tendemos a considerar que, já que as tecnologias atualmente disponíveis permitiriam uma tal facilidade de utilização de recursos multimodais, as práticas textuais tradicionais, quando realizadas em meio digital, sofreriam mudanças radicais. Entretanto, para além das possibilidades e facilidades oferecidas pelos recursos tecnológicos de um meio, há a influência das comunidades discursivas específicas na construção dos textos.

Dentro desta perspectiva, o objetivo do presente artigo é analisar, sob o viés da Semiótica Social, conforme entendida por Kress e Van Leeuwen $(2001,2006)$ e Kress $(2003,2015)$, a orquestração de modos semióticos realizada em revistas acadêmicas eletrônicas gerenciadas e publicadas pelo sistema OJS ${ }^{1}$ (Open Journal Systems) a partir, principalmente, dos quatro estratos relacionados à construção de significados dos textos multimodais: discurso, design, produção e distribuição (KRESS; VAN LEEUWEN, 2001). Para tanto, são analisados, além de dois exemplares dessas revistas eletrônicas - Alfa e Cadernos de Estudos Linguísticos -, informações constantes em manual que trata da utilização do OJS.

Na próxima seção, “A produção de significados na Semiótica Social”, apresentaremos os pressupostos teóricos da Semiótica Social, focando em como essa teoria enxerga o processo de construção de significados e, consequentemente, fornecendo subsídios para que o objeto semiótico aqui analisado seja visto a partir dessa ótica. Considerando que nossa análise acontece a partir de um objeto semiótico, que, além de utilizar recursos tecnológicos digitais, tem uma contrapartida no meio impresso, na terceira seção, "Multimodalidade e Novas Tecnologias", discutiremos como as facilidades oferecidas pelas Novas Tecnologias de Informação e Comunicação influenciam as possibilidades de orquestração dos modos semióticos que constroem os textos.

A quarta seção, "Os estratos de construção de significados dos textos multimodais", é onde nos dedicamos a apresentar os quatro domínios de construção de significado dos textos multimodais - discurso, design, produção, distribuição - indicados em Kress e Van Leeuwen (2001), que servirão à nossa análise das revistas acadêmicas eletrônicas. Na quinta seção, apresentamos os Procedimentos Metodológicos que nortearam nosso trabalho. Já na sexta seção, "A construção de significados nas revistas eletrônicas", procedemos à análise da organização multimodal das revistas acadêmicas eletrônicas a partir, principalmente, dos quatro estratos apresentados na seção anterior, de maneira a relacioná-los e tratá-los em seus pontos de convergência e imbricamento.

\section{A PRODUÇÃO DE SIGNIFICADOS NA SEMIÓTICA SOCIAL}

Para a Semiótica Social, há pelo menos três características que identificam o signo: a de que, diferente do que preconizava Saussure (2012), não há arbitrariedade na relação entre forma e significado dos signos e, por isso, todos os signos são motivados (BEZEMER; KRESS, 2015; HODGE; KRESS, 1988); a de que “[...] o signo é sempre moldado pelo ambiente em que é realizado e pelo seu lugar

${ }^{1}$ O sistema Open Journal Systems (OJS) foi desenvolvido pelo Public Knowledge Project da University of British Columbia e, no Brasil, recebeu o nome de Sistema Eletrônico de Editoração de Revistas (SEER), sendo traduzido e adaptado pelo Instituto Brasileiro de Informação em Ciência e Tecnologia (IBICT). 
nesse ambiente [...]"2 (BEZEMER; KRESS, 2015, p. 9); e a de "[...] que cada modo oferece certos potenciais para fazer significado: cada um tem affordances específicas [...]”3 (BEZEMER; KRESS, 2015, p. 10). Segundo essa abordagem, os signos são frutos de escolhas feitas por agentes, com base em aspectos relativos aos seus interesses, mas também são influenciados pelas práticas sociais onde têm lugar e pelos modos e recursos disponíveis para realizá-los e, por isso, são também convencionalizados (KRESS, 2003).

Para a Semiótica Social, os significados e os modos através dos quais eles são materializados são resultado de ação, de um trabalho semiótico, tanto de articulação dos signos, feito no âmbito da produção de sentidos, pelos agentes que constroem os textos, quanto de interpretação dos signos, realizada pelo trabalho do leitor ou da audiência (KRESS, 2003). Nessa perspectiva, os significados são feitos, construídos, ao invés de apenas estarem disponíveis para serem usados, por isso espera-se que os agentes dessa construção tomem decisões sobre a melhor maneira de expressar o que têm em mente e o que é adequado para a situação e se preocupem com a compreensão da mensagem (KRESS; VAN LEEUWEN, 2006).

Segundo Kress (2015, p. 69),

O conceito de trabalho semiótico assume uma participação social comum na formação de recursos culturais/semióticos. A noção de interesse reconhece o fato de que eu tenho sido moldado e tenho moldado a mim mesmo, nos mundos sociais - nas comunidades - nos quais tenho participado: tendo sido agente no meu engajamento com os recursos de comunidades específicas,culturalmente e semioticamente, moldadas socialmente, utilizando as ferramentas - de qualquer tipo - . moldadas por gerações de pessoas engajadas antes de mim, na minha nova formação de recursos, no meu uso deles. ${ }^{4}$

Essa citação dá destaque para o caráter social do interesse que move os agentes que realizam o trabalho semiótico, ficando claro que, embora haja motivações pessoais para a realização desse trabalho, os sujeitos são resultado também de suas práticas sociais em comunidades específicas, o que influencia as suas escolhas e novas construções semióticas, e também estão sujeitos às possibilidades e restrições dos recursos já construídos nessas comunidades de prática e moldados por elas. Fica evidenciado aí que o trabalho semiótico é palco de um jogo entre forças de estabilidade e instabilidade (BEZEMER; KRESS, 2015): a força de estabilidade é marcada pelas convenções, pelas relações de poder, pelas maneiras de utilização de modos e recursos semióticos associados e moldados por uma comunidade de prática, que influenciam todo trabalho semiótico realizado no interior dela; já a força de instabilidade vem dos agentes que, a partir dos recursos e características disponíveis nessa comunidade, trabalham a partir de seus interesses e das necessidades sociais que surgem para realizar novas ações semióticas específicas.

\section{MULTIMODALIDADE E NOVAS TECNOLOGIAS}

A Semiótica Social, como aqui está sendo tratada, assume que todo texto é sempre multimodal (KRESS; LEITE-GARCIA; VAN LEEUWEN, 1997), de maneira que os modos semióticos que o compõem são orquestrados conforme seus potenciais e limitações, suas affordances, para produzir significado (KRESS, 2003). Sendo "modo" entendido por Kress (2003, p. 45) como "[...] o nome para um recurso moldado socialmente e culturalmente para representação e comunicação [...]" , fica evidenciada sua estreita relação com o meio social em que é realizado e no qual realiza ações. Assim é que a escrita, a imagem e a música, por exemplo, são modos semióticos, cada qual possuidor de affordances que fazem com que eles sejam mais ou menos adequados para a construção de significados específicos em contextos sociais também específicos.

\footnotetext{
${ }^{2}$ No original: "The sign is always shaped by the environment in which it is made, and its place in that environment".

${ }^{3}$ No original: "[...] each mode offers certain potentials for making meaning: each has specific affordances".

${ }^{4}$ No original: "The concept of semiotic work assumes a common social participation in the shaping of cultural/semiotic resources. The notion of interest acknowledges the fact that I have been shaped, and have shaped myself, in the social worlds - in the communities - in which I have participated: having been agentive in my engagement with the resources of socially shaped, culturally and semiotically specific communities, using the tools - of whatever kind - shaped by generations of those engaged before me, in my new shaping of resources, in my use of them".
}

${ }^{5}$ No original: "Mode is the name for a culturally and socially fashioned resource for representation and communication". 
Os modos e suas affordances constroem os textos, os quais, por sua vez, têm um "lugar de aparecimento", que, segundo Kress (2003, p. 48), "[...] tem suas ordenações e regularidades inerentes e culturalmente produzidas, as quais têm efeitos nos textos que aparecem nesses lugares [...]" ${ }^{\prime}$. Esses lugares de aparecimento são estreitamente dependentes das tecnologias de informação e comunicação, as quais são entendidas por Kress (2015, p. 52) como “[...] uma gama de recursos culturais, socialmente feitos, que estão envolvidos na produção do material dos significados; que têm efeitos que dão forma sobre os significados feitos; e que estão envolvidos na exibição e distribuição desses significados-como-textos" ?

Essas tecnologias, disponíveis em uma determinada sociedade e em determinada época para materialização dos seus textos, são, por isso, também vistas, pelos estudos empreendidos na Semiótica Social, como parte do processo de construção de significados dos textos multimodais. A partir dessa perspectiva, as novas tecnologias de informação e comunicação oferecem facilidades para a escolha e a orquestração dos modos (KRESS, 2003; KRESS; VAN LEEUWEN, 2006), cada uma do seu jeito, o que tem permitido uma profusão de textos multimodais produzidos por tantas pessoas e com recursos que antes não eram possíveis.

Dentro desse cenário, Kress (2003) aponta que, atualmente, os textos aparecem dominantemente na tela (digital), a qual, segundo ele, é organizada pela lógica da imagem, diferentemente da página (impressa), cuja lógica é a da escrita. Nesse caso, para Kress, o lugar de aparecimento, por causa dessa lógica, influencia a escolha e o arranjo dos modos que construirão os textos que estão suportados nesses locais, de maneira que, mesmo os textos escritos, quando aparecem na tela, passam a serem regidos pela lógica da imagem, a qual dominará “[...] a ordenação, a forma, a aparência e os usos da escrita [...]”8 (KRESS, 2003, p. 48).

Ainda assim, no caso das revistas acadêmicas eletrônicas em análise, essa lógica é subvertida em vários pontos, por causa da forte influência da prática impressa nos textos digitais no meio acadêmico. Por isso, em determinados momentos, veremos claramente que a lógica da imagem se sobrepõe à da escrita, mas, em outros, a lógica da escrita se sobrepõe à da imagem. Dessa maneira, é preciso ter cautela acerca do verdadeiro papel das novas tecnologias na diversidade de textos multimodais que temos atualmente, pois, conforme Kress (2003, p.49), a facilidade tecnológica sozinha não está liderando essa mudança, mas sim "coincide com mudanças sociais, culturais, econômicas e políticas, que em conjunto estão produzindo e empurrando essa mudança" 9 .

\section{OS ESTRATOS DE CONSTRUÇÃO DE SIGNIFICADOS DOS TEXTOS MULTIMODAIS}

Kress e van Leeuwen (2001) apresentam quatro domínios de prática, estratos, que interagem para construir os significados em textos multimodais, de maneira não hierárquica: discurso, design, produção e distribuição. Os discursos, segundo os autores, são “[...] conhecimentos socialmente construídos de (algum aspecto da) realidade [...]"10 (KRESS; VAN LEEUWEN, 2001, p. 4) e, portanto, são responsáveis pela manutenção ou pela contestação de valores, crenças e ideologias associados às comunidades de prática a partir das quais são construídos. Os discursos são algo subjacente às práticas sociais e podem ser materializados de diferentes maneiras, em diferentes modos, meios, gêneros e textos.

O segundo domínio, o do design, "[...] está no meio do caminho entre conteúdo e expressão [...]"11 (KRESS; VAN LEEUWEN, 2001, p. 5), e constitui o planejamento de como esse conteúdo pode ser expresso, por isso é abstrato, não é ainda a materialização textual e pode nem mesmo chegar a ser. As affordances dos modos e as facilidades das mídias fornecem possibilidades, restrições e

\footnotetext{
${ }^{6}$ No original: “[...] have their inherent and culturally produced orderings and regularities, which have effects on the texts which appear in these sites".

${ }^{7}$ No original: "[...] a range of socially-made, cultural resources, which are involved in making meanings material; which have shaping effects on the meanings made; and which are involved in the display and distribution of these meanings-as-texts".

${ }^{8}$ No original: “[...] the ordering, shape, appearance and uses of writing”.

${ }^{9}$ No original: "[...] the technological facility coincides with social, cultural, economic and political changes, all of which together are producing and pushing that change".

${ }^{10}$ No original: "[...] socially constructed knowledge of (some aspect of) reality".

${ }^{11}$ No original: "Design stands midway between content and expression".
} 
ferramentas para a construção dos textos, mas é o planejamento de quais e como esses elementos serão arranjados, com que objetivo, para que audiência, em quais contextos sociais, em que ambiente que possibilita que os textos multimodais realizem ações de fato (KRESS, 2003). Esse planejamento é o que a Semiótica Social chama de "design", uma projeção dos interesses do realizador do texto para tomar decisões sobre o arranjo que um determinado produto textual assumirá.

O terceiro domínio é o da produção, que se refere à "[...] organização da expressão, à articulação material atual do evento semiótico ou à produção material atual do artefato semiótico[...]”12 (KRESS; VAN LEEUWEN, 2001, p. 6). Esse é o domínio que concerne mais especificamente ao meio material de execução, enquanto o domínio do design trata mais especificamente dos modos semióticos. Entretanto, como asseveram Kress e Van Leeuwen (2001), muitas vezes é difícil separar esses dois domínios, pois, como dito anteriormente, os recursos tecnológicos e suas possibilidades e restrições disponibilizados em um meio, em um lugar de aparecimento, influenciam a orquestração dos modos semióticos que terão lugar nele (por exemplo, permitindo alguns modos e outros não ou tornando obrigatórias determinadas composições multimodais) e, assim, as caraterísticas do meio de produção tornam-se um elemento importante que o realizador do texto deverá levar em conta ao planejar um produto semiótico, ao elaborar seu design.

O domínio da distribuição é responsável pela "preservação e distribuição"13 (KRESS; VAN LEEUWEN, 2001, p. 7) de um produto semiótico, pelas maneiras e lugares pelas quais ele se apresenta à sua audiência. Embora esse domínio tenda a não ser visto como importante no processo de construção de significados (KRESS; VAN LEEUWEN, 2001), ele pode interferir no processo semiótico na medida em que as formas de apresentação de um texto podem modificar suas características e, consequentemente, as maneiras como a audiência irá interagir com ele e construir significados a partir dele, o que deve ser levado em conta no processo de design e produção. Esse domínio torna-se particularmente importante diante da grande quantidade de meios de veiculação de produtos semióticos, possibilitados pelas novas tecnologias.

Essa importância fica evidenciada quando observamos, por exemplo, a possibilidade de veiculação de produtos semióticos em múltiplas telas (computador, tablet, celular). A depender da tela em que um site ou aplicativo é acessado, pode haver modificações na organização dos modos que os compõem para facilitar a leitura ou para permitir funcionalidades específicas relacionadas ao aparelho de veiculação. Essas adaptações são programadas/planejadas (portanto, influenciam o design) e são executadas (no domínio da produção) a depender da maneira como o produto semiótico será distribuído. Se não há, por parte do responsável pelo site ou aplicativo, a preocupação com a distribuição do produto que construiu, esse produto pode ser desconfigurado em sua organização semiótica ou não servir às funções para as quais foi planejado, o que pode inviabilizar a interação do público com ele, simplesmente porque o meio de distribuição foi alterado.

\section{PROCEDIMENTOS METODOLÓGICOS}

Para empreender nossas análises, observamos duas revistas eletrônicas da área de linguística: Alfa, que é publicada pela UNESP/Araraquara, e Cadernos de Estudos Linguísticos, publicada pela UNICAMP. Para chegar a esses dois exemplares de revistas acadêmicas eletrônicas, primeiramente empreendemos uma pesquisa na plataforma de busca Google, a partir dos termos revista linguística. Gerados os resultados de busca, utilizamos dois critérios para escolher as revistas que seriam utilizadas em nossas análises. O primeiro e mais básico consistiu em escolher apenas revistas eletrônicas que fossem gerenciadas pelo sistema OJS (Open Journal Systems), que é o foco deste estudo. O segundo foi o de que as revistas fossem classificadas pelo sistema Qualis-Periódicos/CAPES ${ }^{14}$ no estrato Al na área de Letras/Linguística (escolhida pela nossa maior familiaridade com suas práticas), o que nos permitiria

\footnotetext{
${ }^{12}$ No original: "[...] to the organization of expression, to the actual material articulation of the semiotic event or the actual material production of the semiotic artifact".

${ }^{13}$ No original: “[...] preservation and distribution”.

${ }^{14}$ O Qualis-Periódicos é “[...] um sistema usado para classificar a produção científica dos programas de pós-graduação no que se refere aos artigos publicados em periódicos científicos” (COORDENAÇÃO DE APERFEIÇOAMENTO DE PESSOAL DE NÍVEL SUPERIOR, 2014).
} 
observar revistas que fossem vistas como importantes ou representativas pela comunidade acadêmica dessa área, considerando que, em grande parte, essa percepção é influenciada pela avaliação realizada por esse sistema.

Ressaltamos que, embora saibamos ser possível visualizar listas de periódicos classificados em cada estrato Qualis por meio da página $<$ https://qualis.capes.gov.br/ $\geq$, preferimos utilizar um sistema de busca mais popular para nos aproximarmos da experiência de busca na internet mais cotidiana, em que os primeiros resultados mostrados acabam ficando em posição de evidência, o que pode induzir o leitor a se contentar com eles e não buscar outros links nas demais páginas de resultados. É por isso também que os dois critérios de escolha mencionados anteriormente foram aplicados somente aos resultados de busca que apareciam na primeira página de resultados do Google, o que nos fez chegar às duas revistas mencionadas neste trabalho.

Esse procedimento é justificado a partir da nossa crença de que, se, ao digitarmos esses termos de busca, as duas revistas aparecem entre as primeiras posições da lista de resultados, elas passam a constituir um paradigma relevante para esse leitor, que prefere se concentrar nos primeiros resultados, sobre como é a aparência de uma revista Qualis Al da área de Linguística, o que pode balizar a percepção desse sujeito em relação a outras revistas acadêmicas. Além disso, acreditamos que a observação de duas revistas é suficiente para nossa análise, visto que o nosso foco não consiste na comparação entre as peculiaridades inerentes a cada revista gerenciada pelo OJS, mas sim nas possibilidades e restrições oferecidas por esse sistema para a orquestração de modos semióticos que se materializa nas publicações que escolhemos, assim como se materializa nas outras publicações gerenciadas pelo mesmo sistema.

Escolhidas as revistas eletrônicas e sabendo que elas podem ser acessadas em diferentes telas, delimitamos nosso trabalho apenas à sua versão para desktop/computador, ou seja, aquela que é feita para ser vista em telas de computadores de mesa e notebooks. Esse recorte tornou-se necessário considerando a possibilidade de haver modificação na maneira como os sites se apresentam, a depender da tela (celular ou tablet, por exemplo) em que são visualizados, o que nos demandaria uma análise comparativa que não faz parte especificamente dos nossos propósitos para essa pesquisa, embora possa ser objeto de estudos futuros.

Tendo em vista nosso objetivo de analisar a orquestração de modos semióticos realizada nas revistas acadêmicas eletrônicas gerenciadas e publicadas pelo sistema OJS com foco nos quatro estratos relacionados à construção de significados dos textos multimodais (discurso, design, produção e distribuição), coletamos também informações constantes no manual ${ }^{15}$ que trata da utilização do OJS, para que fosse possível verificar as intenções que podem ter guiado a construção desse sistema de publicação de revistas e os possíveis efeitos que essa construção causa no produto semiótico (a revista eletrônica) e no público que o interpreta. Assim, as informações do manual nos permitiram entender as possibilidades e restrições oferecidas pelo sistema OJS, principalmente no que se refere ao que é passível de ser modificado pelos editores das revistas e o que é fixo, o que nos propiciou o entendimento de como as imposições do sistema e as modificações realizáveis pelos editores interagem nos quatro estratos e se materializam de maneira específica nos sites das revistas que analisamos.

\section{A CONSTRUÇÃO DE SIGNIFICADOS NAS REVISTAS ELETRÔNICAS}

Grande parte das revistas acadêmicas eletrônicas brasileiras é gerenciada e publicada pelo OJS, seja esse sistema usado em sua versão original ou em sua versão brasileira, o Sistema Eletrônico de Editoração de Revistas (SEER), que é recomendado pela CAPES. Esse sistema, conforme seu manual,

[...] busca reduzir o tempo e a energia devotados às tarefas administrativas e de secretariado associadas à produção de uma revista, enquanto melhora a preservação dos registros e a eficiência dos processos editoriais. Busca também aperfeiçoar a qualidade da publicação científica e acadêmica através de várias inovações, desde a transparência das políticas ao aprimoramento da indexação da revista (INSTITUTO BRASILEIRO DE INFORMAÇÃO EM CIÊNCIA E TECNOLOGIA, 2006, p. 6)

\footnotetext{
15 O manual que aqui analisamos foi traduzido pelo Instituto Brasileiro de Informação em Ciência e Tecnologia (IBICT). Em $<$ https://pkp.sfu.ca/files/OJSinanHour.pdf>, é possível encontrar o manual em sua língua original.
} 
Esses objetivos declarados para a existência do sistema, que é baseado em software livre, parecem relacionados apenas a funcionalidades administrativas e técnicas. Entretanto, as possibilidades e restrições oferecidas pelos recursos tecnológicos disponibilizados pelo sistema (que, sendo baseado em software livre, busca constantemente ser melhorado por meio da colaboração de seus usuários) têm consequências para a orquestração de significados materializada na interface dos sites construídos por meio dele, que revelam aspectos da ideologia típica das práticas acadêmicas.

Quando se observa uma comunidade de prática específica, como a acadêmica, por exemplo, que é aqui de nosso interesse, verificase que há um discurso comum inerente a todos os textos que são produzidos a partir dela e que se manifesta nos diferentes modos e arranjos semióticos que são escolhidos para compô-los. Em relação especificamente à comunidade discursiva acadêmica, o discurso que permeia seus textos é o da valorização da padronização, da normatização, da institucionalidade, da impessoalidade, da objetividade e da expertise, que, como veremos ao longo deste trabalho, está presente também no arranjo das revistas acadêmicas eletrônicas.

Ao falarmos no processo de articulação de significados envolvidos na produção das revistas eletrônicas através do OJS, torna-se complicado separar responsabilidades de design e de produção, visto que grande parte do que é materializado na produção já é predeterminado pelo sistema e vale para qualquer revista que utilize suas ferramentas, mas há também uma série de escolhas que são feitas pelos responsáveis pela elaboração de cada revista.

De acordo com Bezemer e Kress (2015, p. 112) " “...] neste nível da aparência, o texto é composto por uma complexa interação entre diferentes tipos de 'designers' (designers de plataformas e algoritmo e os autores dos textos individuais) e leitores, em formas típicas das plataformas digitais [...]"16. Assim, consideramos que, nesse caso, o design relacionado ao planejamento da publicação de uma revista eletrônica é derivado de um processo anterior de escolha e formatação das possibilidades e restrições do sistema como um todo, feito pelos seus programadores, e das escolhas de orquestração de significados realizadas pelos responsáveis de cada revista, dentro dos limites impostos pelo design do sistema. Em vista disso, a produção dessas revistas evidencia a interação dos componentes derivados das duas fontes.

Do ponto de vista da articulação de significados, as escolhas de design evidenciadas nas revistas eletrônicas gerenciadas pelo OJS indicam valorização da padronização e da simplificação, o que é confirmado pela citação mencionada anteriormente, que apresenta os objetivos do sistema e permite entrever que há a ideia de que ele realizaria e simplificaria tarefas administrativas e técnicas para que o corpo editorial da revista se concentre de fato nas tarefas editoriais.

Visto que a estrutura dos sites baseados nesse sistema, mesmo que com adaptações, é reproduzida massivamente, fica subentendido que as escolhas em relação ao aspecto visual da produção da revista eletrônica são consideradas mais técnicas, mais previsíveis, ao ponto de serem padronizadas. Essa maneira de lidar com as escolhas de design fornece, em grande parte, uma identidade visual marcada e padronizada ao conjunto de revistas publicadas através do OJS - assemelhando-se às normas tácitas vigentes na comunidade acadêmica para a formatação de seus textos e permitindo que a audiência (mais experiente, em geral) possa perceber que está em uma revista eletrônica e navegá-la com mais propriedade - e restringe as possibilidades multimodais que poderiam ser utilizadas para personalização da revista, considerando as tantas ferramentas disponibilizadas em meio digital para isso.

\footnotetext{
${ }^{16}$ No original: "On this level of appearance, text is composed through a complex interaction between different types of 'designers' (platform and algorithm designers and the authors of individual texts) and readers, in ways typical of digital platforms".
} 


\begin{tabular}{cccccc}
\hline CAPA & SOBRE ACESSO CADASTRO PESQUISA ATUAL ANTERIORES NOTÍCIAS \\
\hline Capa & Cadernos de Estudos linguísticos
\end{tabular}

\section{CADERNOS DE ESTUDOS LINGUÍSTICOS}

É um periódico quadrimestral de Linguística patrocinado pelo Departamento de Linguística (DL) do Instituto de Estudos da Linguagem (IEL) da
Universidade Estadual de Campinas (UNICAMP).

Está aberto a contribuições sobre questões de interesse cientifico em qualquer sub área da Linguística e em qualquer das seguintes línguas: português, inglês, francếs, espanhol.

O seu Conselho Editorial é composto, principalmente, de docentes do próprio $\mathrm{DL}$, mas conta também com alguns membros externos de expressão

na comunidade cientifica nacional e internacional.

Os trabalhos submetidos são arbitrados por membros do próprio conselho e por assessores ad hoc.

Além de artigos isolados, a revista aprecia propostas de organização de números monográficos por pesquisadores de reconhecida competência na área da Lingǘistica em que se insere o número pretendido.
OPEN JOURNAL SYSTEMS

Ajuda do sistema

USUÁRIO

Login

Senha

$\square$ Lembrar usuário

Acesso

IDIOMA

$\longdiv { \text { Português (Brasil) } \downarrow }$

CONTEÚDO DA REVISTA

Pesquisa

Todos

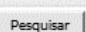

Por título

Outras revistas

INFORMAÇÕES

Para leitores

Figura 1: Página Inicial da revista eletrônica “Cadernos de Estudos Linguísticos”

Fonte: Caderno de Estudos Linguísticos (1978-)

Em geral, as revistas eletrônicas geridas pelo OJS, ao serem acessadas, apresentam um aspecto parecido ao da Figura 1, com modificações nas cores e no logo que representa a revista. Há um cabeçalho com as cores representativas da revista, em geral monocromáticas, ocupando a parte superior da página, na qual é alocado o logo da revista. Abaixo do cabeçalho, no menu horizontal, chamado, no manual de utilização do sistema (INSTITUTO BRASILEIRO DE INFORMAÇÃO EM CIÊNCIA E TECNOLOGIA , 2006), de "Barra de Navegação", são apresentadas as seções do site, sendo frequente a divisão e a ordem que são evidenciadas na imagem.

É importante ressaltar que, embora as seções do menu possam ser acessadas em qualquer ordem, de acordo com os objetivos do usuário que acessa o site, é provável que haja, no processo de design do site, uma preocupação com a indicação de uma ordem adequada de acesso às seções. Um desses indícios é a presença da seção "CAPA" ocupando a primeira posição no menu. A escolha por essa nomeação revela uma associação com um elemento típico das revistas impressas, que constitui o primeiro elemento com o qual, quase que obrigatoriamente, o leitor tem contato ao manusear esse suporte. Entretanto, diferentemente das capas de revistas impressas, além do logo da revista eletrônica e dos logos dos sistemas que a indexam (esses últimos na parte inferior da página), não costuma haver imagens nessa página inicial.

Em relação ao design das revistas eletrônicas construídas a partir do OJS, é possível afirmar que há um foco na padronização, o que fica claro pela maneira de construir as revistas: através do preenchimento de formulários, os quais possibilitam a atualização dos campos ligado à personalização da revista de acordo com as especificidades que apresenta em relação a outras revistas. As atualizações permitidas são, em sua maioria, concernentes ao texto verbal, ficando as possibilidades de escolha de textos não verbais geralmente restritas à imagem do cabeçalho, às cores utilizadas na página e às imagens das capas de cada edição da revista.

Essa característica evidencia uma aproximação com as práticas textuais acadêmicas em geral, que são fortemente calcadas no texto verbal. Nesse caso, ainda que as revistas eletrônicas estejam alocadas em sites, o que, em tese, permite uma ampla possibilidade de orquestração de modos, o discurso acadêmico acaba por agir através da padronização do OJS, restringindo essa orquestração, em grande parte, aos modos tradicionalmente usados nas revistas acadêmicas impressas. 
A relação entre o design planejado para essas revistas eletrônicas e aquele típico das revistas acadêmicas impressas fica evidenciada, por exemplo, quando, ao verificarmos a produção de uma dessas revistas, acessamos o menu “Atual”, que leva à última edição publicada:
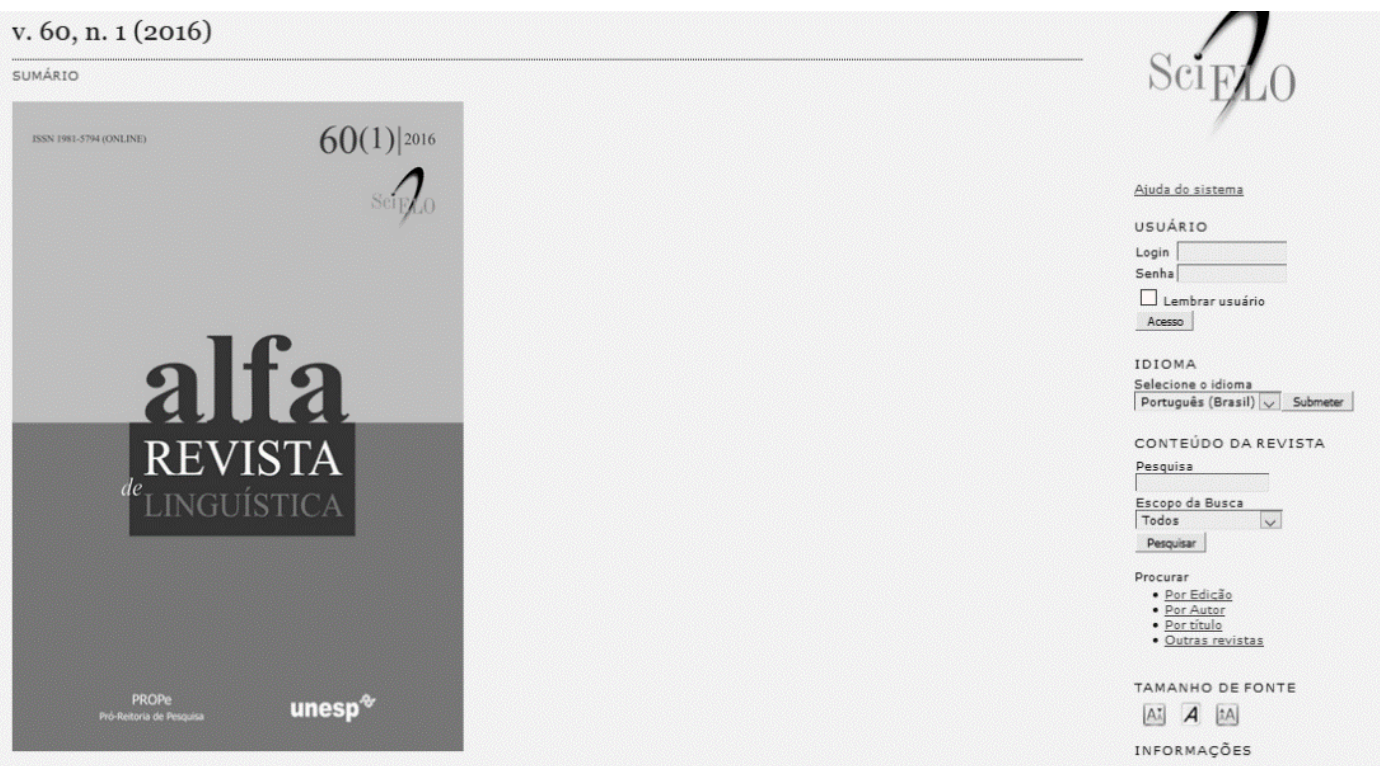

Figura 2: Capa de edição da Revista Alfa

Fonte: Alfa (2016)

Na Figura 2, vemos uma imagem que se assemelha à capa de publicações periódicas acadêmicas impressas e, ao clicarmos nessa "capa", somos direcionados para a seguinte tela:

\begin{tabular}{|c|c|c|}
\hline CAPA sobre acesso cadastro pesquisa atual antertores & & OPEN JOURNAL SYSTEMS \\
\hline \multicolumn{3}{|l|}{ Capa > Edị̂̃es anteriores > v. 60, n. 1 (2016) } \\
\hline \multicolumn{3}{|l|}{ v. 60 , n. 1 (2016) } \\
\hline \multicolumn{3}{|l|}{ Edição completa } \\
\hline Ver ou baixar a edição completa & PDF PDF (ENGUSH) & \\
\hline \multirow{2}{*}{\multicolumn{2}{|c|}{ Sumário }} & Aluds do sietema \\
\hline & & USUARIO \\
\hline Apresentação & PDF POF (ENGUSH) & $\operatorname{Login}_{\operatorname{Sanhs}}$ \\
\hline \multicolumn{3}{|l|}{ Artigos Originais } \\
\hline $\begin{array}{l}\text { A invencão colonial das linguas da América } \\
\text { Cristine Gorski Severo }\end{array}$ & PDF PDF (ENGUSH) & 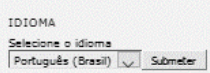 \\
\hline $\begin{array}{l}\text { Demonstrativos na România medievali: uma análise comparativa em uma perspectiva funcional } \\
\text { César Nardelli Cambraia, Teresa Cristina Alves de Melo, Cynthia Elias de Leles Vilaça, Thiago César Viana Lopes Saltarelli }\end{array}$ & PDF PDF (ENGLSH) & $\begin{array}{l}\text { CONTEUDD DA REVISTA } \\
\text { PegqUUSS }\end{array}$ \\
\hline $\begin{array}{l}\text { Uma microanálise de cartas oficiais Norte-Rio-Grandenses } \\
\text { Felipe Morais de Melo, Maria Hozanete Alves de Lima }\end{array}$ & PDF PDF (ENGUSH) & 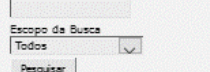 \\
\hline $\begin{array}{l}\text { Cartografias das Linquas: Glossários para livros de literatura } \\
\text { Vanise Medeiros }\end{array}$ & PDF PDF (ENGUSH) & $\begin{array}{l}\text { Prourar } \\
\text { P Por EGicajo }\end{array}$ \\
\hline $\begin{array}{l}\text { Evolución léxico-terminolóacica de las enfermedades raras: revisión de los diccionarios de la Real Academia Española } \\
\text { Susana Ridao Rodrigo, Francisco José Rodríguez Muñoz }\end{array}$ & PDF PDF (ENGUSH) & 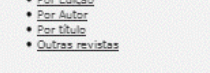 \\
\hline $\begin{array}{l}\text { Desenvolvimento da protoarcumentacão na interacão adulto-bebê } \\
\text { Angelina Nunes de Vasconcelos, Selma Leitão }\end{array}$ & PDF PDF (ENGUSH) & $\begin{array}{l}\text { TaManho de Fonte } \\
{[A] \boldsymbol{A}[\text { [A] }}\end{array}$ \\
\hline $\begin{array}{l}\text { Professor da escola bísica representado na escrita reflexiva acadêmica do aluno mestre } \\
\text { Wagner Rodrigues Silva, Elaine Espindola }\end{array}$ & PDF PDF (ENGLSH) & $\begin{array}{l}\text { INF ORMAÇOES } \\
\text { Para leitores }\end{array}$ \\
\hline
\end{tabular}

Figura 3: Sumário de edição da revista Alfa

Fonte: Alfa (2016) 
Na figura 3, vemos um Sumário, com aspecto semelhante ao das publicações impressas, com informações dispostas em blocos lineares, de cima para baixo. À direita do nome de cada artigo, no lugar da designação das páginas, comum nos sumários das publicações impressas, há links para acessar os arquivos em PDF dos artigos. É possível afirmar que, nesse caso, embora haja uma distinção derivada da diferença entre os recursos dos meios de materialização textual (o impresso faz sua ligação entre sumário e conteúdo através de numeração de páginas, enquanto, para o digital, a possibilidade mais adequada para fazer essa ligação é a utilização de links), uma manutenção do construto visual tipicamente associado a um sumário procura ser mantida.

Quando falamos da relação entre audiência e domínios da construção do texto multimodal, há evidências de que os domínios de design e produção operam visando a uma audiência presumida ou público-alvo e o domínio de distribuição é o que de fato proporciona o contato entre esses outros dois domínios e a audiência real, a qual não coincide necessariamente com a audiência presumida. No caso em análise, infere-se que a audiência presumida é composta por indivíduos que já possuem algum grau de imersão nas práticas discursivas da comunidade acadêmica e possuem habilidades para navegar e agir utilizando os produtos digitais produzidos no interior dessas práticas.

Embora a padronização apresentada pelas revistas produzidas e gerenciadas pelo OJS seja derivada, em grande parte, dos próprios recursos oferecidos pelo sistema e das limitações que ele impõe, não há como afirmar que o público que acessa essas revistas, a audiência real, tem plena consciência do seu processo de articulação. Assim, o produto semiótico multimodal apresentado nesses sites, quando passa pelo processo de interpretação da sua audiência real, é visto conforme se apresenta no seu meio de distribuição e as experiências desse público que, se tiver tido contato anterior com a prática de produção acadêmica na internet e perceber a ampla padronização das revistas eletrônicas, pode facilmente navegar nos menus, seções e caixas de busca ou preenchimento de informações para realizar as ações que deseja.

Mesmo na hipótese de que, na produção das revistas, não fosse levado em conta o que é aceitável ou desejável para a comunidade acadêmica, mas apenas as características técnicas e administrativas para realizar determinadas ações, ainda assim, no momento do trabalho de interpretação feito pelo público, a maneira de apresentação do produto semiótico é percebida à luz do que esse público conhece sobre as práticas acadêmicas, pois o processo de interpretação precisa da ancoragem nas práticas da comunidade discursiva responsável pelo produto semiótico. No entanto, no caso de usuários menos experientes, pode haver dificuldades relacionadas à construção visualmente pouco atrativa e pouco intuitiva dessas revistas, que difere da profusão de orquestração de modos que é comumente vista na web, assim como à apresentação muito próxima da que se mostra nas revistas acadêmicas impressas, voltadas para um público específico.

\section{CONCLUSÃO}

A partir dos pressupostos vigentes na Semiótica Social, foi possível entender que, embora haja uma ampla disponibilidade e facilidade de recursos tecnológicos para produção de textos atualmente, esses recursos não respondem sozinhos pelas possíveis mudanças em relação às possibilidades de orquestração de modos semióticos disponíveis, já que as ideologias e regularidades das comunidades de prática discursiva que produzem os objetos semióticos influenciam fortemente o trabalho semiótico operado a partir deles.

Esse fato foi constatado na análise das revistas acadêmicas eletrônicas construídas a partir do OJS como objetos semióticos, visto que os quatro estratos de construção de significado em textos multimodais, envolvidos no trabalho semiótico de articulação e interpretação dessas revistas revelaram-se fortemente influenciados pelas ideologias e práticas, inclusive práticas textuais anteriores, da comunidade discursiva acadêmica. Assim, mesmo que as facilidades do meio tecnológico tenham levado a adaptações para que as publicações acadêmicas tivessem lugar no meio digital, os modos escolhidos e a utilização das affordances desses modos nessas publicações continuam bastante baseados nas práticas tradicionais impressas dessa comunidade discursiva. 


\section{REFERÊNCIAS}

ALFA: REVISTA DE LINGUÍSTICA. São Paulo: UNESP, v. 60, n. $1, \quad 2016 . \quad$ Disponível em: <http://seer.fclar.unesp.br/alfa/issue/view/550http://seer.fclar.unesp.br/alfa/issue/view/550>. Acesso em: 06 jul. 2016.

BEZEMER, J.; KRESS, G. Multimodality, learning and communication: a social semiotic frame. London: Routledge, 2015.

CADERNO DE ESTUDOS LINGUÍSTICOS. Campinas: UNICAMP, 1978- . Quadrimestral. ISSN 0102-5767. Disponível em: $<$ http://revistas.iel.unicamp.br/index.php/cel/>. Acesso em: 06 jul. 2016.

COORDENAÇÃO DE APERFEIÇOAMENTO DE PESSOAL DE NÍVEL SUPERIOR. Classificação da Produção Intelectual, 01 abr. 2014. Disponível em: <http://www.capes.gov.br/avaliacao/instrumentos-de-apoio/classificacao-da-producao-intelectual>. Acesso em: 10 jul. 2016.

INSTITUTO BRASILEIRO DE INFORMAÇÃO EM CIÊNCIA E TECNOLOGIA. OJS em uma hora: introdução ao sistema eletrônico de editoração de revistas SEER/OJS versão 2.1.1. Tradução Ramón Martins Sodoma da Fonseca. Revisão Carlos Roberto Meinert. [S.l.: s.n.], 2006. Disponível em: <http://seer.ibict.br/images/stories/file/manuais/ojs_uma_hora.pdf >. Acesso em: 06 jul. 2016.

HODGE, R.; KRESS, G. Social semiotics. Cambridge: Polity Press, 1988.

KRESS, G. Literacy in the new media age. London and New York: Routledge, 2003.

KRESS, G. Semiotic work: Applied Linguistics and a social semiotic account of Multimodality. AILA Review, Amsterdam, n. 28, 2015. 49-71.

KRESS, G. R.; LEITE-GARCIA, R.; VAN LEEUWEN, T. Discourse semiotics. In: VAN DIJK, T. Discourse as structure and process. London; Thousand Oaks; New Delhi: Sage Publications, 1997. p. 256-291.

KRESS, G.; VAN LEEUWEN, T. Multimodal discourse: the modes and media of contemporary communication. London: Arnold, 2001.

KRESS, G.; VAN LEEUWEN, T. Reading images: The grammar of visual design. 2. ed. London: Routledge, 2006.

SAUSSURE, F. Curso de linguística geral. 34. ed. São Paulo: Cultrix, 2012. 